\title{
Perancangan Sistem Informasi Absensi Asisten Lab Berbasis Android pada Universitas Pamulang
}

\author{
Alvino Octaviano ${ }^{1}$, Sofa Sofiana ${ }^{2}$, Satrio Pandita Priyadi ${ }^{3}$ \\ Program Studi Teknik Informatika, Fakultas Teknik, Universitas Pamulang \\ Kampus UNPAM Viktor, Tangerang Selatan \\ e-mail: 1'dosen00397@ unpam.ac.id, ${ }^{2}$ sofiana82@gmail.com, ${ }^{3}$ satriopriadi8@ gmail.com \\ Submitted Date: September $09^{\text {th }}, 2020$ \\ Reviewed Date: October $08^{\text {th }}, 2020$ \\ Revised Date: November $02^{\text {nd }}, 2020$ \\ Accepted Date: November $02^{\text {nd }}, 2020$
}

\begin{abstract}
Fingerprint recognition with distance-based optimization and pattern matching, "international conference on signal processing, communication, power, and data management systems on attendance paper makes it very difficult to log absent and absent assistants. In this case Change of attendance records to save. in a digital-based information system database. Meanwhile, fingerprint attendance methods or methods have been used on cellphones. Record attendance. Method makes applications that support digital attendance with Android. Android is an operating system application for mobile phones based on Linux. Android offers developers an open platform where they can create their own applications used by various mobile devices.
\end{abstract}

Keywords: Fingerprint Recognition; Information System; Android

\begin{abstract}
Abstrak
Pengenal sidik jari dengan pengoptimalan hibrid berdasarkan jarak dan pencocokan pola, konferensi internasional tentang pemrosesan sinyal, komunikasi, daya, dan sistem pengelolaan data pada kertas kehadiran membuat sangat sulit untuk mencatat asisten yang absen dan tidak hadir. Dalam hal ini Perubahan pencatatan absensi untuk disimpan dalam database sistem informasi berbasis digital. Sementara itu, metode atau metode absensi sidik jari telah digunakan pada ponsel. Rekam absensi. Metode membuat aplikasi yang mendukung absensi digital dengan Android. Android merupakan aplikasi sistem operasi untuk telepon seluler Berbasis Linux. Android menawarkan pengembang platform terbuka tempat mereka dapat membuat aplikasi mereka sendiri yang digunakan oleh berbagai perangkat seluler.
\end{abstract}

Kata Kunci: Pengenalan Sidik Jari; Sistem Informasi; Android

\section{Pendahuluan}

Masa sekarang ini perkembangan teknologi dan sistem informasi sudah semakin pesat, kehidupan dan teknologi adalah dua hal yang hampir mustahil untuk dipisahkan. Teknologi informasi ditujukan untuk membantu pekerjaan dengan menyediakan informasi dan melakukan berbagai tugas yang berhubungan dengan pengolahan informasi (Hanum \& Saifudin, 2019). Perkembangan teknologi dan sistem informasi yang demikian pesat di era globalisasi sekarang ini telah membuat hampir semua aspek kehidupan tidak dapat dihindarkan dari penggunaan teknologi. Melalui sistem database digital bisa mempengaruhi (Fadila, 2019).
Setiap absen yang diberikan pada setiap Asisten Lab tidaklah sama karena pemberian absen yang adil dan sesuai dengan pekerjaan masingmasing, yaitu harus berdasarkan kinerja yang dilaksanakan atau sesuai dengan syarat lainnya yang dimiliki oleh setiap program studi.

Yayasan Sasmita Jaya memiliki tujuan mewujudkan suatu sarana pendidikan yang murah dan terjangkau oleh seluruh lapisan masyarakat tanpa melupakan kualitas dari pendidikan itu sendiri. Oleh karena itu Universitas Pamulang selalu mengangkat tenaga pengajar dan staff administrasi yang berkompeten di bidangnya. Kamipun juga melakukan pengembangan di bidang kurikulum yang disesuaikan dengan kebutuhan 
dunia kerja, sehingga seluruh lulusan Universitas Pamulang diterima dengan pada dunia kerja.

Algoritma ini dijalankan untuk mengurangi ukuran kompleksitas program secara keseluruhan dengan pengakuan dan meningkatkan kecepatan eksekusi. Hasil pengenalan sidik jari adalah hasil 99\% dan juga mencapai $0,4 \%$.

Sistem pengolahan absensi karyawan asisten lab masih dilakukan secara tertulis, kemudian absensi karyawan asisten lab tersebut di data dalam bentuk form kertas, lalu setelah itu data pada form kertas tersebut dimasukkan manual ke dalam microsoft excel untuk data secara komputerisasi. Hal tersebut sangat tidak efisien dan efektif dari segi waktu dan data pada form kertas tersebut sangat rentan akan kerusakan atau hilang.

Untuk itulah program studi Teknik Informatika memerlukan aplikasi basis data dalam pengolahan data-data absensi agar sistem absensi karyawan (asisten lab) di program studi tersebut dapat berjalan secara efektif dan efisien terutama dari segi waktu. Data yang sudah tersimpan di dalam komputer juga harus melakukan backup secara berkala sebagai data cadangan, sehingga apabila terjadi hal yang tidak diinginkan data tersebut masih ada. Dengan adanya aplikasi absensi karyawan "asisten lab" diharapkan pehitungan akan lebih cepat dan akurat serta lebih membantu pekerjaan yang ada.

\section{Landasan Teori}

\subsection{Tujuan Pustaka}

Studi literatur merupakan penulisan yang bersumber dari buku media pakar atau dari hasil penelitian orang lain memiliki tujuan untuk menyusun dasar teori yang akan digunakan dalam melakukan penelitian. Pada penelitian ini ada beberapa jurnal dari penelitian sebelumnya.

Penelitian yang dilakukan oleh Jagad (Kusumayudha, 2015) pada penulisannya, penelitian ini membahas tentang Perancangan Sistem Absensi Pada Smk Mulia Buana Berbasis Web, penelitian dilakukan untuk mengetahui prosedur, kelebihan, kekurangan, peluang, dan kendala. Penelitian ini juga bertujuan untuk memperbaiki sistem absensi yang ada di SMK MULIA BUANA karena sistem absensi yang masih manual atau dengan kertas. Oleh karena itu, peneliti menyarankan agar menggunakan web untuk aplikasi absensinya.

Penelitian ini membahas tentang perancangan sistem informasi absensi guru dan staf Tata Usaha pada SMA Negeri 14 Tangerang (Inayah, 2012), penelitian yang bertujuan untuk memperbaiki sistem absensi guru dan staff tu karena sistem yang masih manual menggunakan buku absensi yang harus diisi setiap hari di ruang piket. Oleh karena itu, peneliti mengusulkan penggunaan web pada sistem absensi agar mudah dalam merekap semua data.

\subsection{Sistem}

Sistem juga merupakan kesatuan bagian-bagian yang saling berhubungan yang berada dalam suatu wilayah serta memiliki item-item penggerak, contoh umum misalnya seperti negara. Negara merupakan suatu kumpulan dari beberapa elemen kesatuan lain seperti provinsi yang saling berhubungan sehingga membentuk suatu negara di mana yang berperan sebagai penggeraknya yaitu rakyat yang berada di negara tersebut.

\subsection{Data}

Suatu sistem penyusunan dan pengelolaan record-record dengan menggunakan komputer dengan tujuan untuk menyimpan serta memelihara data operasional lengkap suatu perusahaan atau organisasi, sehingga mampu menyediakan informasi yang optimal yang diperlukan maka untuk proses pengambilan keputusan (Kristanto, 2012).

\subsection{Sistem Informasi}

Sistem informasi adalah suatu sistem yang ada di dalam suatu organisasi yang mempertemukan kebutuhan pengolahan transaksi harian, mendukung operasi yang bersifat manajerial dan kegiatan strategi dari suatu organisasi dan pihak luar tertentu dengan laporan yang diperlukan. (Zakiyudin, 2012). Sedangkan dari sumber lain, sistem informasi adalah kumpulan dari sub-sub sistem yang saling terintegrasi dan berkolaborasi untuk menyelesaikan masalah tertentu dengan cara mengolah data sehingga memiliki nilai tambah dan bermanfaat bagi pengguna (Taufiq, 2018).

\subsection{Analisa Pada Sistem}

Tahap analisis sistem merupakan tahap yang kritis dan sangat penting, karena kesalahan di dalam tahap ini akan menyebabkan juga kesalahan di tahap selanjutnya. Tahapan ini bisa merupakan tahap yang mudah jika client sangat paham dengan masalah yang dihadapi dalam organisasinya dan tahu betul fungsionalitas dari sistem informasi yang akan dibuat. Tetapi tahap ini bisa menjadi tahap yang paling sulit jika client tidak bisa mengidentifikasi kebutuhannya atau tertutup 
terhadap pihak luar yang ingin mengetahui detaildetail proses bisnisnya.

\subsection{Perancangan Sistem}

Perancangan sistem merupakan suatu fase di mana diperlukan suatu keahlian perancangan untuk elemen-elemen komputer yang akan menggunakan sistem (Kristanto., 2012), yaitu pemilihan peralatan dan program komputer untuk sistem komputer yang baru.

\section{Analisa Dan Perancangan}

\subsection{Analisa Sistem}

Analisa sistem adalah proses untuk menentukan hal-hal detail tentang yang akan dikerjakan oleh sistem yang diusulkan (dan bukan bagaimana caranya). Tahapan analisa sistem dilakukan untuk mengembangkan sistem yang sudah ada atau mengatasi masalah-masalah yang belum tertangani.

\subsection{Perancangan Pada Basis Data}

Basis data merupakan kumpulan file yang saling berkaitan satu dengan yang lainnya di mana model data relational atau hubungan antarfile direlasikan dengan kunci relasi (relational key) yang merupakan kunci primer dari masing-masing file. Basis data tersimpan pada simpanan luar komputer digunakan perangat lunak tertentu untuk memanipulasinya. Pada perancangan basis data ini akan diuraikan mengenai Entity Relationship Diagram (ERD), transformasi ERD ke LRS, Logical Record Structure (LRS), dan struktur tabel dari Aplikasi Fingerprint Berbasis Android di Universitas Pamulang.

Entity Relationship Diagram merupakan pemodelan jaringan yang menggunakan susunan data yang disimpan pada sistem secara abstrak:

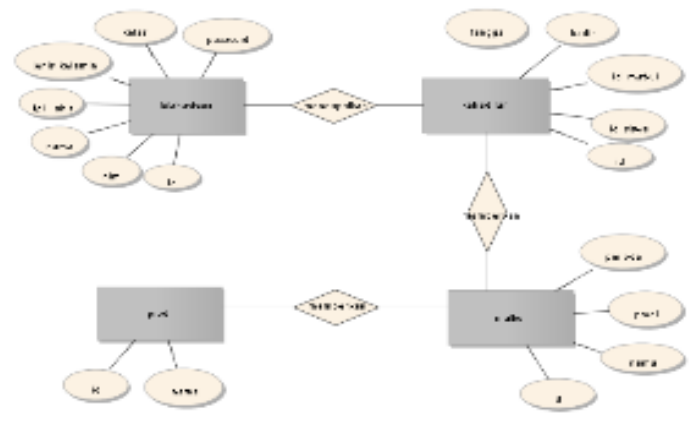

Gambar 3.1 Entity Relationship Diagram

\subsection{Perancangan Sistem/Aplikasi}

Rancang sistem secara umum dilakukan dengan maksud untuk memberikan gambaran umum tentang sistem yang baru atau sistem yang akan diusulkan. Rancangan ini mengidentifikasi komponen-komponen sistem informasi yang dirancang secara rinci.

Berikut adalah Perencanaan Aplikasi dari sistem yang diusulkan.

\subsubsection{Use Case Diagram}

Di dalam perancangan ini akan menjelaskan tentang bagaimana instansi melakukan aktivitas kepegawaian dengan Sistem yang diusulkan. Use case diagram menggambarkan secara grafis perilaku software/aplikasi. Adapun use case diagram di bawah ini adalah use case diagram Sistem Absensi Finggerprint berbasis Android.

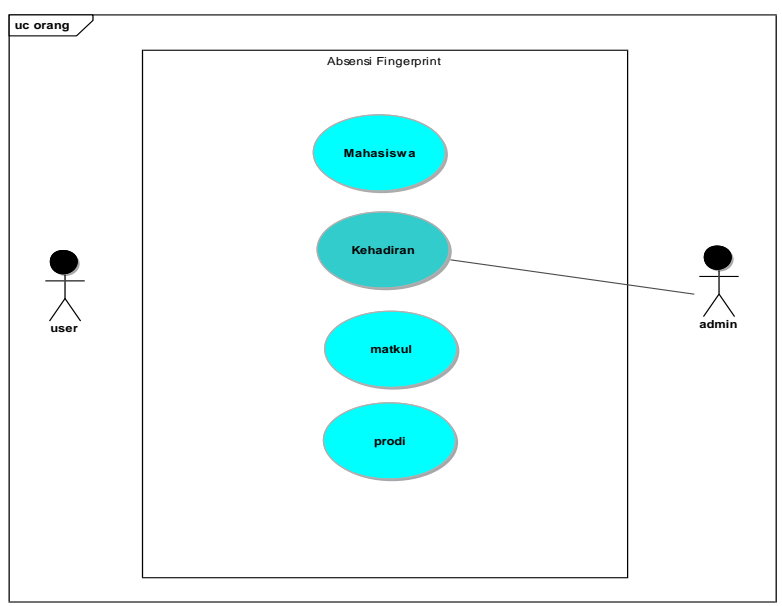

Gambar 3.2 Use Case Diagram

Berikut ini adalah penjelasan dari hasil perancangan use case diagram di atas:

a. Mahasiswa melakukan login terlebih dahulu

b. Program studi dapat mengelola tabel Matkul

c. Mahasiswa melakukan absen kehadiran

d. Kehadiran dapat melakukan absen kehadiran ngajar

e. Matkul dapat mencetak Matkul

\subsubsection{Sequence Diagram}

Sequence diagram adalah grafik dua dimensi di mana objek ditunjukkan dalam dimensi horizontal sedangkan lifeline ditunjukkan dalam dimensi vertical, masing masing sequence diagram akan menggambarkan aliran aliran pada suatu use case. 


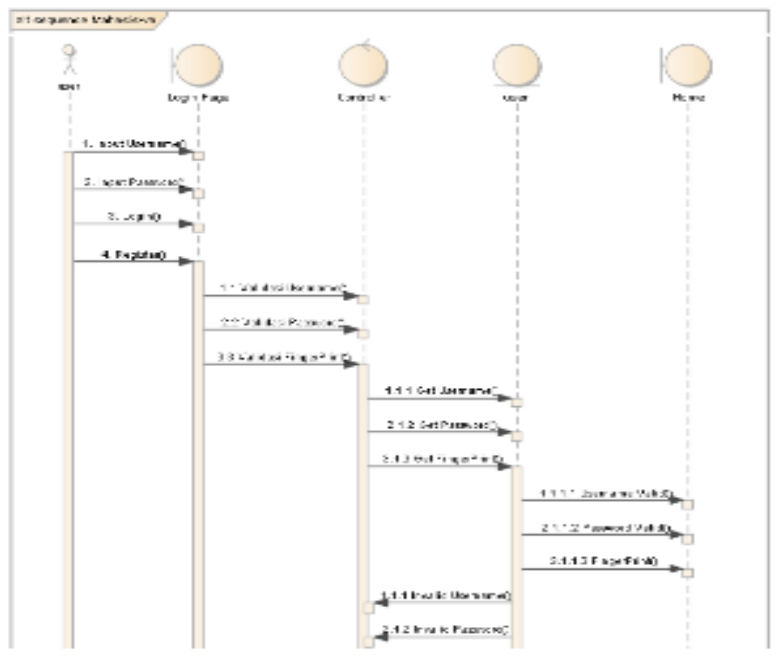

Gambar 3.4 Use Case Admin

User membuka halaman di mana form login berada, kemudian masukkan username dan password serta type user. Jika username dan password benar, maka sistem akan menampilkan halaman utama Dashboard. Jika username dan password salah, maka user harus memasukkan kembali username dan password yang benar.

\subsubsection{Activity Diagram}

Activity diagram menggambarkan berbagai alir aktivitas dalam sistem yang sedang dirancang, bagaimana masing-masing alir berawal dan yang mungkin terjadi dan memperlihatkan aliran kendali dari suatu aktifitas lainnya. Adapun Activity Diagram yang diusulkan sebgai berikut:

\section{Activity Mahasiswa}

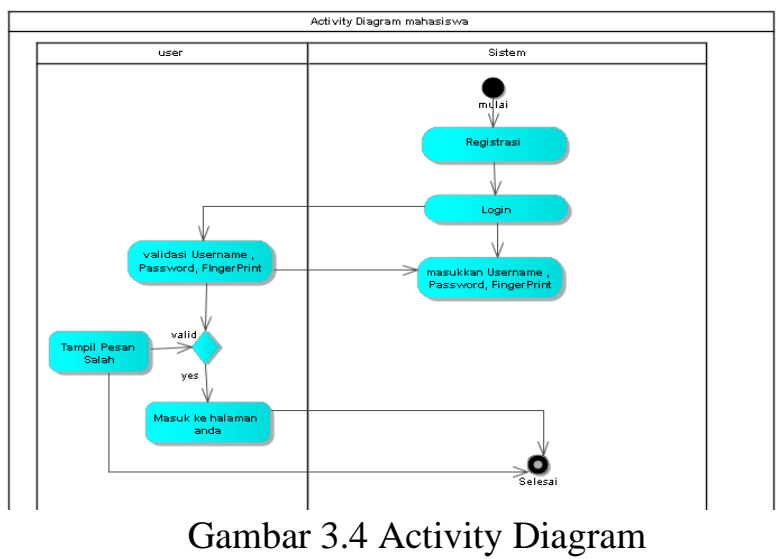

Sistem menampilkan halaman form login kemudian memasukkan username, password, fingerprint dan tipe user. Jika username, password, fingerprint dan tipe user benar, maka sistem akan menampilkan Dashboard. Jika username, password salah, maka user harus memasukkan kembali username dan password yang benar.

\subsubsection{User Interface}

Pada gambar 3.14 merupakan perancangan antarmuka di halaman utama terdapat login.

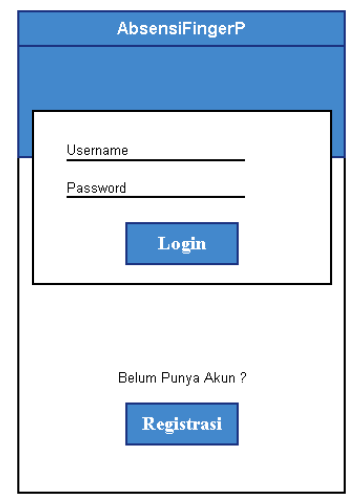

Gambar 3.5 User Interface

\section{Implementasi dan Pengujian}

\subsection{Implementasi}

Implementasi sistem merupakan tahap peletakan sistem sehingga siap dioperasikan. Implementasi bertujuan untuk mengkornfirmasi modul-modul perancangan sehingga pengguna bisa memberi masukan ke pengembang sistem.

\subsubsection{Spesifikasi Pada Perangkat Lunak}

Karena aplikasi yang dikerjakan berbentuk website, berikut list perangkat lunak yang dibutuhkan untuk mengimplementasikan sistem, yaitu pada Tabel 4.1 Spesifikasi Pada Perangkat Lunak (Software).

Tabel 4.1 Spesifikasi Pada Perangkat Lunak (Software)

\begin{tabular}{|c|c|}
\hline $\begin{array}{c}\text { Perangkat } \\
\text { Lunak }\end{array}$ & Keterangan \\
\hline Sistem Operasi & $\begin{array}{c}\text { Windows }{ }^{\circledR} \\
\text { Server 2012 }\end{array}$ \\
\hline Jaringan & Localhost \\
\hline Web Browser & $\begin{array}{c}\text { Google Chrome } \\
\text { dan Mozilla Firefox }\end{array}$ \\
\hline Code Editor & Android Studio \\
\hline
\end{tabular}

\subsubsection{Spesifikasi Perangkat Keras}

Perangkat keras (Hardware) yang digunakan dapat berupa komputer atau laptop sebagai penunjang implementasian. Adapun perangkat 
keras yang dibutuhkan tersebut, yaitu pada Tabel 4.2 Spesifikasi Perangkat Keras (Hardware).

Tabel 4.2 Spesifikasi Perangkat Keras (Hardware)

\begin{tabular}{|l|l|}
\hline $\begin{array}{c}\text { Perangkat } \\
\text { Keras }\end{array}$ & \multicolumn{1}{|c|}{ Keterangan } \\
\hline Processor & $\begin{array}{l}\text { Intel Xeon E3-1220v5 3.0GHz } \\
\text { Turbo 3.5Ghz 8MB Cache }\end{array}$ \\
\hline RAM & 8 GB \\
\hline Harddisk & $\begin{array}{l}3 \times \text { Internal 3.5”HDD Bays } \\
1 \times \text { Internal 2.5”Disk Bay }\end{array}$ \\
\hline VGA & $\begin{array}{l}\text { Aspeed AST1400 with 64MB } \\
\text { VRAM }\end{array}$ \\
\hline Jaringan & 2 x Intel® I210AT \\
\hline Chipset & Intel® C232 Chipset \\
\hline
\end{tabular}

\subsubsection{Implementasi Antarmuka (Interface)}

Pengertian sistem antarmuka adalah salah satu layanan yang disediakan sistem operasi sebagai saran interaksi antara pengguna dengan sistem operasi. Antarmuka adalah komponen sistem operasi yang bersentuhan langsung dengan pengguna. Terdapat 2 (dua) jenis antarmuka, yaitu Command Line Interface (CLI) dan Graphical User Interface (GUI). Berikut ini adalah implementasi setiap antarmuka yang dibuat:

a. Tampilan Halaman Login Admin

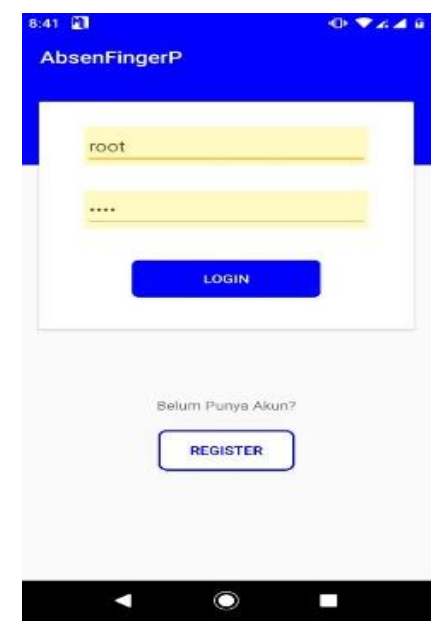

Gambar 4.1 Tampilan Halaman Login Admin

Halaman Login Admin hanya admin yang dapat login. Lalu Fingerprint admin sebagai configurasi kecocokannya.
b. Tampilan
Halaman
Login
Admin

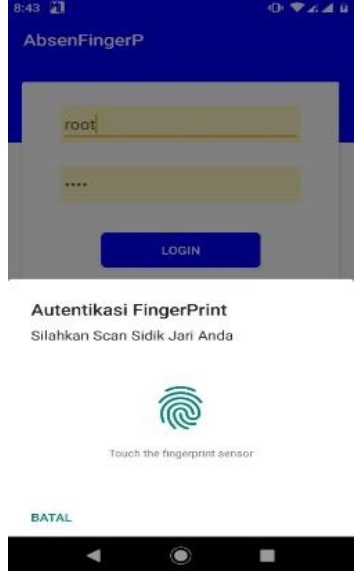

Gambar 4.2 Tampilan Halaman Login Admin Fingerprint

Login admin menggunakan verifikasi fingerprint untuk mengkonfirmasi bahwa penggunanya hanya admin atau program studi.

c. Tampilan Halaman Registrasi

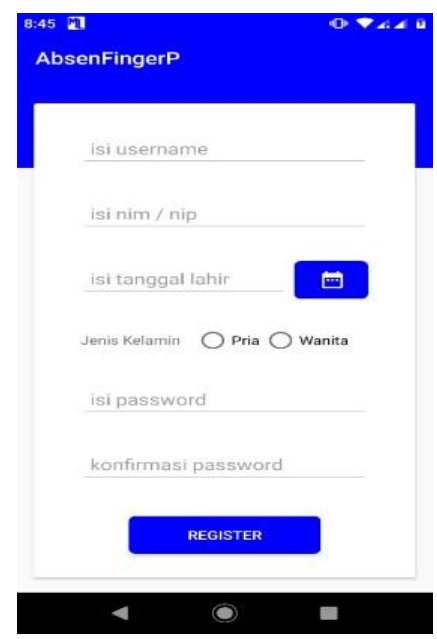

Gambar 4.3 Tampilan Halaman Registrasi

Registrasi diperbolehkan hanya untuk anggota asisten lab saja.

d. Tampilan Halaman Menu Utama Login Admin 


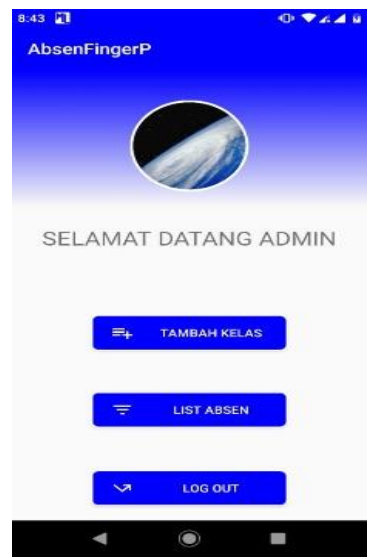

Gambar 4.4 Tampilan Halaman Menu Utama Admin.

Tampilan menu utama pada halaman login admin. Lalu ada beberapa tombol sebagai berikut:

1. Tambah Kelas untuk membuka kelas atau membuka absen mata kuliah buat asisten lab

2. List Absen untuk melihat siapa saja yang sudah absen di mata kuliah tersebut

3. Log Out untuk keluar dari akun admin

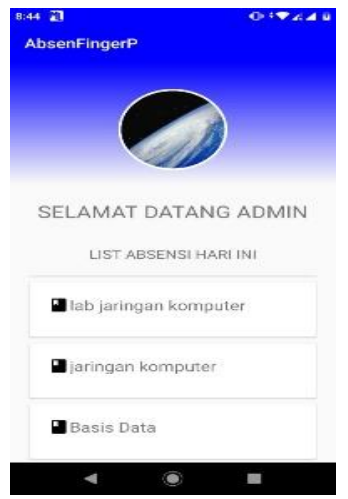

Gambar 4.5 Tampilam Halaman List Absensi Harian Admin e. Tampilan Halaman List Absensi Harian Admin

Tampilan halaman list absensi harian ditunjukkan pada gambar 4.5. Tampilan halaman list absensi harian hanya untuk melihat siapa saja yang sudah absen di hari ini.

\subsection{Pengujian Perangkat Lunak 4.2.1 Pengujian Black Box}

Untuk menjamin kualitas sistem/aplikasi yang dikembangkan harus melalui tahap pengujian (Pratala, Asyer, Prayudi, \& Saifudin, 2020). Pengujian merupakan bagian utama dari pengembangan software, karena kegagalan pengujian dapat menimbulkan kerugian yang besar (Aziz, Setiawan, Khanh, Nurdiyansyah, \& Yulianti, 2020). Pengujian black box dilakukan untuk menguji apakah sistem yang dikembangkan sesuai dengan apa yang tertuang dalam spesifikasi fungsional sistem. pengujian black box adalah pengujian yang memverifikasi hasil eksekusi aplikasi berdasarkan masukan yang diberikan (data uji) untuk memastikan fungsional dari aplikasi sudah sesuai dengan persyaratan (requirement) (Febrian, Ramadhan, Faisal, \& Saifudin, 2020). Black Box juga digunakan untuk menguji fungsifungsi khusus dari perangkat lunak yang dirancang. Kebenaran perangkat lunak yang diuji hanya dilihat berdasarkan keluaran yang dihasilkan dari data atau kondisi masukan yang diberikan untuk fungsi yang ada tanpa melihat bagaimana proses untuk mendapatkan keluaran tersebut.

Skenario pengujian berfungsikan untuk mengelompokan masing-masing sistem yang akan diuji. Skenario black box akan diuraikan pada tabel Tabel 4.1 Pengujian Login Admin

Tabel 4. 1 Pengujian Login Admin

\begin{tabular}{|l|l|l|l|}
\hline \multicolumn{1}{|c|}{ Deskripsi } & \multicolumn{1}{c|}{ Hasil yang Diharapkan } & \multicolumn{1}{c|}{ Hasil Pengujian } & Kesimpulan \\
\hline $\begin{array}{l}\text { Input Username, Password } \\
\text { dan Fingerprint }\end{array}$ & $\begin{array}{l}\text { Berhasil masuk dan diarahkan } \\
\text { kemenu utama admin (home) }\end{array}$ & $\begin{array}{l}\text { Dapat masuk ke } \\
\text { halaman utama admin } \\
\text { (home) }\end{array}$ & Berhasil \\
\hline $\begin{array}{l}\text { Input Username, Password } \\
\text { dan Fingerprint yang tidak } \\
\text { terdaftar di dalam database }\end{array}$ & $\begin{array}{l}\text { Gagal login dan Fingerprint } \\
\text { dan ada peringatan, Failed to } \\
\text { login dan Fingerprint salah! }\end{array}$ & $\begin{array}{l}\text { Tidak dapat masuk ke } \\
\text { halaman utama admin } \\
\text { (home) }\end{array}$ & Berhasil \\
\hline Button tambah kelas & $\begin{array}{l}\text { Berhasil masuk dan diarahkan } \\
\text { ke menu Tambah Kelas }\end{array}$ & $\begin{array}{l}\text { Dapat masuk ke } \\
\text { halaman tambah kelas }\end{array}$ & Berhasil \\
\hline
\end{tabular}

\subsubsection{Pengujian White Box}

Pengujian black box dilakukan untuk menguji apakah sistem yang dikembangkan sesuai dengan apa yang tertuang dalam spesifikasi fungsional sistem. White box juga digunakan untuk menguji fungsi-fungsi khusus dari perangkat lunak 
yang dirancang. Kebenaran perangkat lunak yang diuji hanya dilihat berdasarkan keluaran yang dihasilkan dari data atau kondisi masukan yang diberikan untuk fungsi yang ada tanpa melihat bagaimana proses untuk mendapatkan keluaran tersebut.

Tabel 4.5 Login Admin

\begin{tabular}{|c|c|c|c|}
\hline \\
\hline Pengujian & Test Case Benar & Test Case salah & Kesimpulan \\
\hline $\begin{array}{l}\text { loginbtn.setOnClickListener(new } \\
\text { View.OnClickListener() \{ } \\
\text { public void onClick(View v) } \\
\text { biometricPrompt.authenticate } \\
\text { (promptInfo); } \\
\text { \} } \\
\text { \}); }\end{array}$ & $\begin{array}{l}\text { Berhasil masuk } \\
\text { dan diarahkan ke } \\
\text { menu utama } \\
\text { admin }\end{array}$ & $\begin{array}{l}\text { Tidak dapat } \\
\text { diarahakan } \\
\text { kemenu utama } \\
\text { admin }\end{array}$ & Berhasil \\
\hline $\begin{array}{l}\text { final EditText username }=(\text { EditText }) \\
\text { findViewById(R.id.userid })\end{array}$ & $\begin{array}{l}\text { Berhasil masuk } \\
\text { dari username }\end{array}$ & $\begin{array}{l}\text { Tidak dapat } \\
\text { masuk dari } \\
\text { username }\end{array}$ & Berhasil \\
\hline $\begin{array}{l}\text { final EditText password = (EditText) } \\
\text { findViewById(R.id.password); }\end{array}$ & $\begin{array}{l}\text { Berhasil masuk } \\
\text { dari password }\end{array}$ & $\begin{array}{l}\text { Tidak dapat } \\
\text { masuk dari } \\
\text { password }\end{array}$ & Berhasil \\
\hline $\begin{array}{l}\text { final BiometricPrompt.PromptInfo } \\
\text { promptInfo = new } \\
\text { BiometricPrompt.PromptInfo.Builder() } \\
\text {.setTitle("Autentikasi FingerPrint") } \\
\text {.setSubtitle("") } \\
\text {.setDescription("Silahkan Scan Sidik } \\
\text { Jari Anda") } \\
\text {.setNegativeButtonText("BATAL") } \\
\text {.build(); }\end{array}$ & $\begin{array}{l}\text { Berhasil masuk } \\
\text { dengan fingerprint }\end{array}$ & $\begin{array}{l}\text { Tidak dapat } \\
\text { masuk dengan } \\
\text { fingerprint }\end{array}$ & Berhasil \\
\hline
\end{tabular}

\section{Penutup}

\subsection{Kesimpulan}

Berdasarkan uraian uraian yang telah penulis paparkan pada bab-bab sebelumnya, maka penulis dapat menarik beberapa kesimpulan sebagai berikut:

a. Dengan menggunakan aplikasi ini, data absensi asisten lab di Universitas Pamulang lebih efisien dari sebelumnya.

b. Dengan menggunakan aplikasi ini, pengolahan data absensi asisten lab lebih cepat karena tidak membuka-buka berkas kertas.

c. Dengan menggunakan aplikasi ini dapat mempermudah dalam proses pembuatan laporan yang lebih detail dan terdokumentasi secara teratur.

\subsection{Saran}

Dari implementasi pengujian aplikasi absensi asisten lab ini, Diharapkan adanya pengembangan terhadap perancangan aplikasi absensi asisten lab ini yaitu:

a. Aplikasi tidak hanya dilakukan untuk pengolahan data pada absensi asisten lab saja, akan tetapi bisa diterapkan untuk pengolahan data absensi pada dosen pengajar lainnya.

b. Aplikasi absensi masih dapat dikembangkan, peneliti mengharapkan untuk lebih baik lagi dari aplikasi tersebut, dan bisa digunakan di kampus yang lain

\section{Referensi}

Aziz, I. A., Setiawan, B., Khanh, R., Nurdiyansyah, G., \& Yulianti, Y. (2020). Pengujian Black Box pada Aplikasi Sistem Kasir Berbasis Website Menggunakan Teknik Equivalence Partitions. Jurnal Teknologi Sistem Informasi dan Aplikasi, 3(2), 10.32493/jtsi.v3i2.4693. doi:10.32493/jtsi.v3i2.4693 
Fadila, R. (2019). Pengaruh Penerapan Sistem Absensi Finger Print. Journal of Business Administration, 53-63.

Febrian, V., Ramadhan, M. R., Faisal, M., \& Saifudin, A. (2020). Pengujian pada Aplikasi Penggajian Pegawai dengan menggunakan Metode Blackbox. Jurnal Informatika Universitas Pamulang, 5(1), 61-66. doi:10.32493/informatika.v5i1.4340

Hanum, W. S., \& Saifudin, A. (2019). Rancang Bangun Aplikasi Panduan Pariwisata di Kabupaten Banyuwangi Mobile Berbasis Android. Jurnal Teknologi Sistem Informasi dan Aplikasi, 2(2), 59-65. doi:10.32493/jtsi.v2i2.2798

Inayah, N. (2012). Perancangan Sistem Informasi Absensi Guru Dan Staff Tu Pada Sma Negeri 14 Tangerang. . Tangerang: Perguruan Tinggi Raharja.

Kristanto. (2012). Kecerdasan Buatan. Yogyakarta: Graha Ilmu.

Kusumayudha. (2015). Perancangan Sistem Absensi Pada Smk Mulia Buana Berbasis Web. . Tangerang: Perguruan Tinggi Raharja.

Pratala, C. T., Asyer, E. M., Prayudi, I., \& Saifudin, A. (2020). Pengujian White Box pada Aplikasi Cash Flow Berbasis Android Menggunakan Teknik Basis Path. Jurnal
Informatika Universitas Pamulang, 5(2), 111-119. doi:informatika.v5i2.4713

Taufiq, R. (2018). Pengantar Sistem Informasi. Jakarta: Mitra Wacana Media.

Zakiyudin, A. (2012). Sistem Informasi Manajemen. Jakarta: Mitra Wacana Media. 